\title{
Low-cost and portable automatic sheet cutter
}

\author{
Mohd Syafiq Mispan ${ }^{1}$, Ahmad Hafizzudin Mustafa ${ }^{2}$, Hafez Sarkawi ${ }^{3}$, Aiman Zakwan Jidin ${ }^{4}$ \\ ${ }^{1,4}$ Micro and Nano Electronics (MiNE), Malaysia \\ ${ }^{3}$ Advance Sensors and Embedded Controls System (ASECs), Malaysia \\ ${ }^{1,3}$ Centre for Telecommunication Research and Innovation (CeTRI), Malaysia \\ ${ }^{1,2,3,4}$ Fakulti Teknologi Kejuruteraan Elektrik dan Elektronik, Universiti Teknikal Malaysia Melaka, Malaysia
}

\begin{tabular}{|c|c|}
\hline Article Info & ABSTRACT \\
\hline Article history: & \multirow{9}{*}{$\begin{array}{l}\text { Process automation is crucial to increase productivity, more efficient use of materials } \\
\text { better product quality, improved safety, etc. In small-medium enterprise (SME) } \\
\text { businesses related to household retailing, one of the process automation needed is } \\
\text { the measurement and cutting of the mat or sheet, made of rubber or polyvinyl chloride } \\
\text { (PVC) materials. Most of the household retailers that selling the sheet, the process } \\
\text { of measuring and cutting according to the customer's requirements are manually } \\
\text { performed using a measuring tape and scissors. These manual processes can cause } \\
\text { inaccuracy in length, inefficient use of material, low productivity and reduce produc } \\
\text { quality. This paper presents a low cost and portable automatic sheet cutter using the } \\
\text { Arduino development board, which is used to control the process of measuring and } \\
\text { cutting the materials. The system uses a push-button where the user can set the } \\
\text { required length and quantity of the sheet. Once the required information is set, the step- } \\
\text { per motor rolls the sheet until the required length is satisfied. Subsequently, another } \\
\text { stepper motor moves the cutter horizontally and cut the sheet. With the automatic } \\
\text { sheet cutter, the material is cut with acceptable precision. The design of the automatic } \\
\text { sheet cutter is low cost and portable which significantly suitable to be used by SME } \\
\text { household retailers. }\end{array}$} \\
\hline Received Feb 12, 2020 & \\
\hline Revised Apr 15, 2020 & \\
\hline Accepted Apr 25, 2020 & \\
\hline Keywords: & \\
\hline Arduino & \\
\hline Automation & \\
\hline Cutter & \\
\hline Stepper motor & \\
\hline
\end{tabular}

Copyright $\left({ }_{0} 2020\right.$ Insitute of Advanced Engineeering and Science. All rights reserved.

\section{Corresponding Author:}

Mohd Syafiq Mispan,

Fakulti Teknologi Kejuruteraan Elektrik dan Elektronik, Universiti Teknikal Malaysia Melaka, Malaysia.

Email: syafiq.mispan@utem.edu.my

\section{INTRODUCTION}

Advanced manufacturing industries that involve in the material cutting process, often the process is automated using advanced high-precision cutting machines and widely used within the facilities. The advanced and high precision automatic cutting machine helps in increasing the productivity, quality, and efficiency of the cutting process. Figure 1 illustrates the automatic cutting machine using ultrasonic and electric rotary cutting tools manufactured by S.M.E Engineering which is used for cutting fabric materials [1]. The type of machine that used advanced cutting technology is suitable for high profitable advanced manufacturing industries which demands a high precision cutting machine. Nevertheless, advanced automatic cutter machines are costly and huge. One of the cutting applications in small-medium enterprise (SME) businesses related to household retailing is the cutting of mat or sheet made of rubber or polyvinyl chloride (PVC) materials. The mat/sheet is used as a floor or table mat. Most household retailers adapted the manual process of measuring and cutting using a measuring tape and scissors. However, the manual process often causes inaccuracy in length and inefficient use of materials. To use the aforementioned advanced machines are not suitable for household retailers as they are costly and huge. Moreover, household retailers require an unsophisticated automatic cutting machine with merely acceptable precision. 


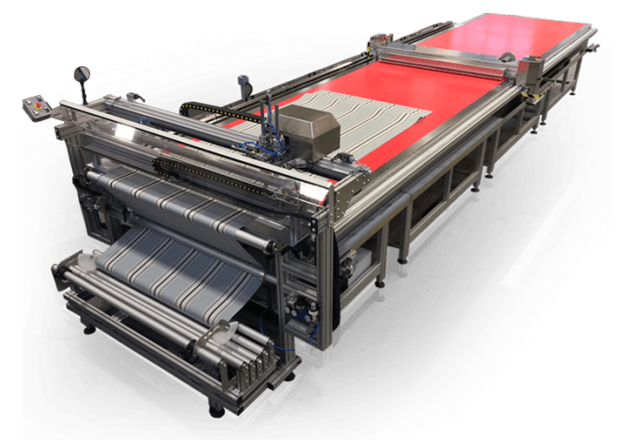

Figure 1. Automatic cutting system with ultrasonic and electric rotary cutting tools [1]

Several automatic cutter machines are proposed in the past. Mende et al., [2] proposed an automatic vegetable leaf cutter using image processing and embedded system techniques. The proposed automatic machine is used to cut the leafy green vegetables which are heavily consumed in restaurants, hotels, wedding ceremony, etc. The image processing technique is used to perform quality checking to separate the good and the bad vegetables by capturing the image of the leaves. The leafy vegetables proceed to the cutting process if its quality is good. Otherwise, the bad leafy vegetables are deposited into the bad quality bin. In a study, an automatic carpet edge-cutting system based on computer vision to improve the production and quality of the product is proposed [3]. A similar approach of using a computer vision technique is proposed in [4, 5]. Another technique of using a laser to cut the paper is proposed in [6]. Jung et al., [7] proposed an automatic cutting machine for glass material in a product line of a touch screen panel. The manual cutting tends to damage the glass due to un-even pressure applied by the workers onto the glass. Hence, the automated glass cutting machine is proposed to improve the production yield rate.

In a recent study, Lakhe et al., [8] designed an automatic cutting machine using a pneumatic technique for metal pipes and rods. The pipe is manually clamped to the machine before the cutting process takes place. Elsewhere, Phakphonhamin et al., [9] conducted a study to optimize the performance of the LECTRA automatic fabric cutting machine. LECTRA is the manufacturer of the advanced automatic cutting machines. The optimization focuses on improving work practices and the workloads of the operator. In the past, a major study was focusing on optimization of the cutting process to improve the reliability, precision, efficiency, wear and tear, etc., [10-22]. In other studies, [23, 24], the automation process to change the cutter tools is proposed.

Based on all the above, generally, the study in the automation of cutting applications can be categorized into two categories which are development and process optimization. This paper focuses on developing the automation system for measuring and cutting the sheet made of rubber or PVC for SME businesses related to household retailing. The automated design receives user inputs such as the length and quantity of the sheet. This information is sent to the Arduino which controlled the process of rolling (i.e., according to the length key-ed in by the user) and cutting the sheet by utilizing two stepper motors. The low-cost components are used to develop the automatic sheet cutter system and the design is portable to suit the demands for SME household retailers. Moreover, the automated sheet cutter is expected to increase the productivity and quality of the product, and increase the efficiency of the material's usage.

\section{METHODOLOGY}

In this section, the methodology to design the low-cost and portable automatic sheet cutter is described. The proposed design must be able to receive two user inputs which are the quantity and the length of the sheet. Based on these specifications, the operation of the automatic sheet cutter is developed as illustrated in Figure 2. The sheet cutter can be operated in a dual-mode which are manual and automatic modes. In the manual operation mode, the user can control the movement of the roller (i.e., used to roll the sheet) or the cutter by pressing up/down or left/right buttons, respectively. In the automatic mode, first, the sheet must be set in a zero (i.e., initial) position. The zero position can be set manually by rolling up or down the sheet using up/down buttons. Once the zero position is achieved, the user can enter the quantity and the length of the sheet. The 
liquid crystal display (LCD) used to display the quality and length of the sheet which was set by the user. The sheet cutter operates automatically according to the given inputs once the start button is pressed.

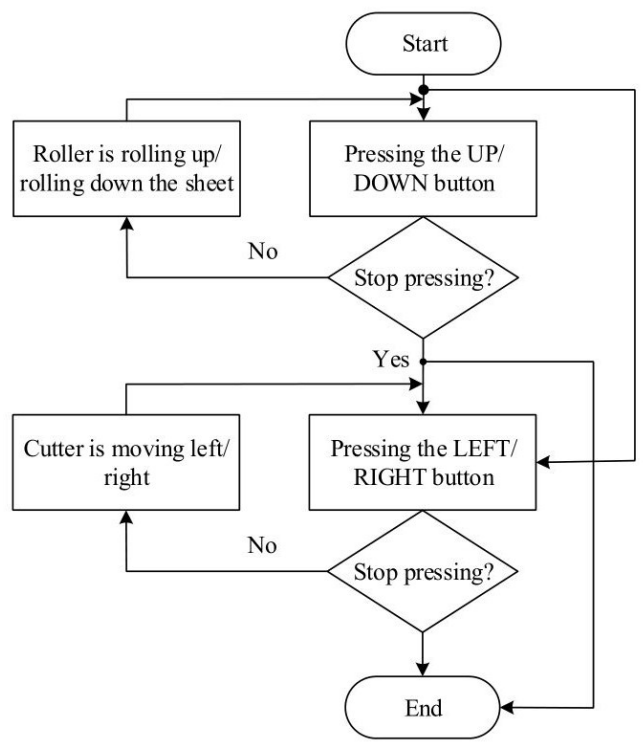

(a)

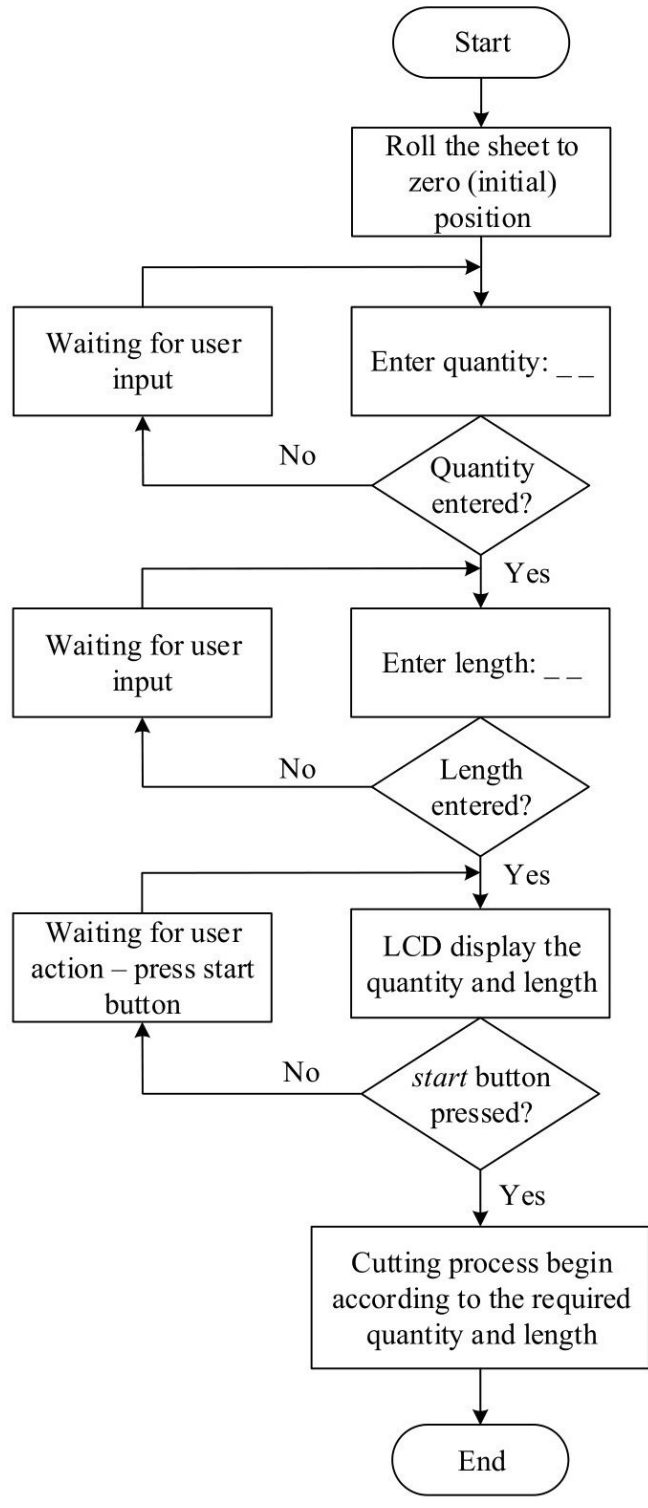

(b)

Figure 2. Operation of the sheet cutter (a) Manual, (b) Automatic

Figure 3 depicts the top-level architecture of the proposed automatic cutter machine to achieve the above requirements. The proposed design can be developed using an Arduino Mega 2560, $2 \times 17 \mathrm{HS} 4401$ stepper motor, $2 \times$ A 4988 stepper motor driver, $2 \times 4$ push-button and I2C 2004 Serial LCD. The user inputs such as length, quantity, movement of the roller, movement of the cutter, and start are set using push-button. The Arduino board received and processed the user inputs to produce outputs that are used to controls the information display on the LCD and the movement of the stepper motors. Following the design in [25], two stepper motors are used to control the movement of the roller and cutter, respectively. A driver is needed to drive the stepper motor which requires a supply voltage of $12 \mathrm{~V} \mathrm{DC}$. On the other hand, an Arduino board requires a supply voltage of $8 \mathrm{~V} \mathrm{DC}$. Therefore, a power supply circuit is required which consists of a step-down transformer (240V AC to $12 \mathrm{~V} \mathrm{AC}$ ), AC-to-DC converter, and step-down converter (12V DC to 8V DC). 


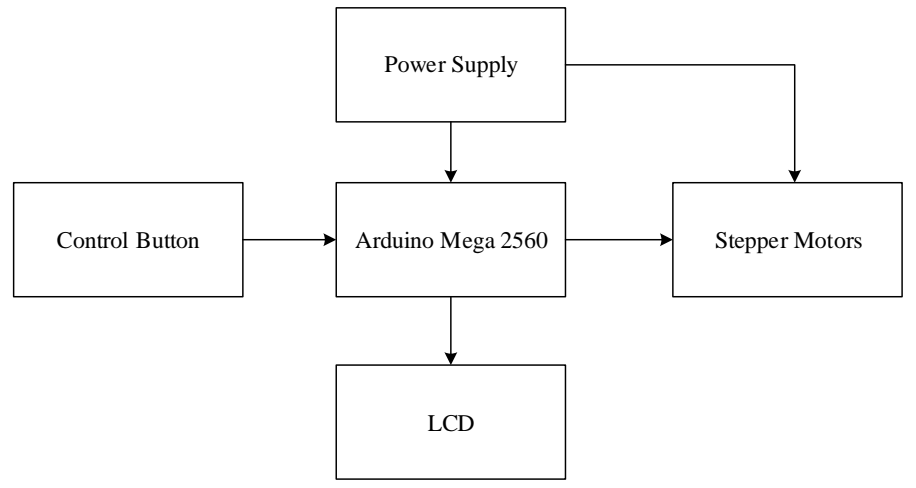

Figure 3. Top-level architecture of the proposed automatic sheet cutter.

\section{RESULT AND ANALYSIS}

Figure 4 illustrates the prototype of a fully functional automatic sheet cutter that has been built based on the requirements and components described in Section 2.. The prototype consists of three main parts which are the roller-cutter framework, Ardunio-based controller circuitry, and sheet racking tool. Figure 4a illustrates the roller-cutter framework. The base of the framework is made of steel. As can be seen in Figure 4a, two stepper motors are used to control the movement of the roller and cutter, respectively. The roller is made of rubber material to achieve a maximum grip of the sheet. The roller-cutter framework is designed to have hook-shaped ends such that it can be easily attached or detached (i.e., portable) to the sheet racking tool. The Arduino-based controller circuitry is shown in Figure $4 \mathrm{~b}$ which has an extra feature of a cooling fan system. The power supply circuit outputs two different voltages of $12 \mathrm{~V}$ and $8 \mathrm{~V}$ DC to supply the stepper motor driver and Arduino development board, respectively. The sheet racking tool is constructed following the existing design used in the household retail shops as depicted in Figure 4c.

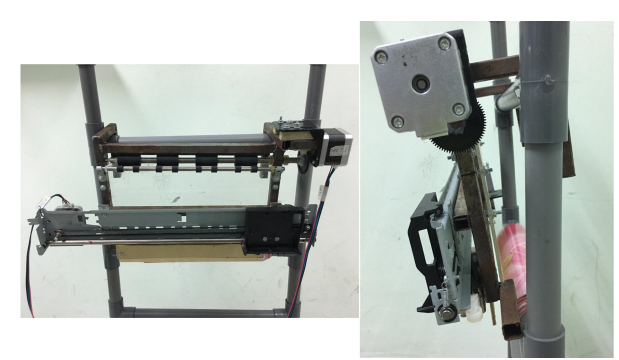

(a)

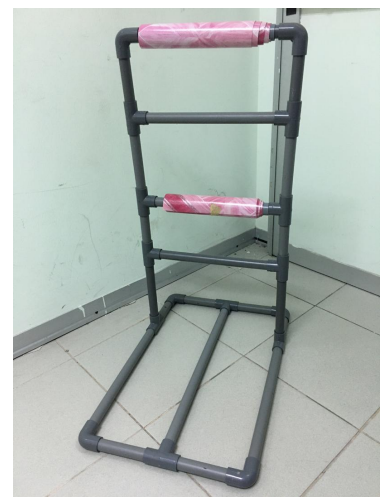

(c)

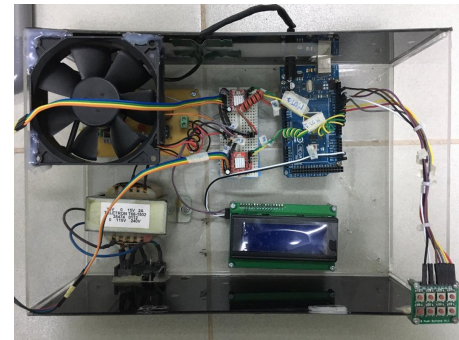

(b)

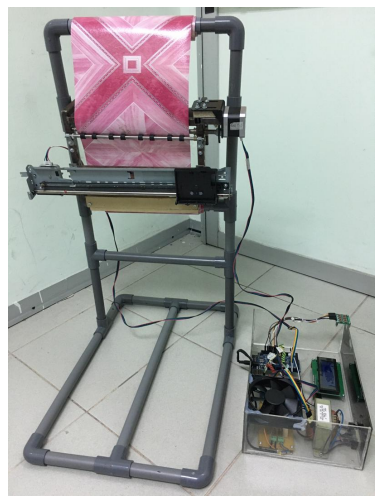

(d)

Figure 4. Prototype of the fully functional automatic sheet cutter (a) Close-up view of the roller-cutter framework, (b) Arduino-based controller circuitry, (c) Sheet racking tool, (d) Zero position 
When the system is powered-up, the LCD displays two modes of operations which are manual and auto, as shown in Figure 5a. A manual mode operation allows the user to simply move the roller or cutter by pressing appropriate push-button, as described in Figure 2a. Before selecting the auto mode, the user has to set the sheet in a zero (initial) position which can only be done in manual mode. A zero position is achieved when the sheet's end is perpendicular to the cutter's blade. Once a zero position is achieved, the auto mode can be selected which displays the sequence of the menu as illustrated in Figure 5b. The user has to key-in the quantity and length of the sheet. To start the cutting process, the user has to push the start button. The LCD displays 'CUTTING' indicating the process of cutting and 'FINISH' is displayed once the cutting process completed.

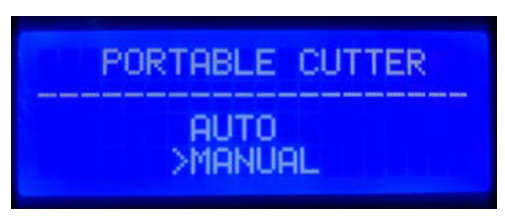

(a)

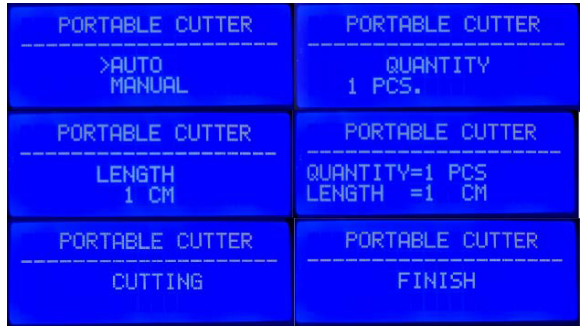

(b)

Figure 5. LCD menu (a) Main display, (b) Auto menu

Table 1. Comparison of the required length and the cut length for quantity $>1$

\begin{tabular}{ccc}
\hline Required Length $(\mathrm{cm})$ & Cut Length $(\mathrm{cm})$ & $|\Delta|(\mathrm{cm})$ \\
\hline 5 & 5.4 & 0.4 \\
5 & 4.9 & 0.1 \\
5 & 5.2 & 0.2 \\
10 & 10.3 & 0.3 \\
10 & 10.1 & 0.1 \\
10 & 10.3 & 0.3 \\
\hline
\end{tabular}

The performance of the automatic sheet cutter in Figure 4 is measured and analyzed using Root Mean Square Error (RMSE) as described in (1), where $\hat{y}_{i}$ is the predicted value, $y_{i}$ is the target value and $n$ is the number of measurements.

$$
R M S E=\sqrt{\sum_{i=1}^{n} \frac{\left(\hat{y}_{i}-y_{i}\right)^{2}}{n}}
$$

Table 1 shows the accuracy of the automatic sheet cutter when the length is set to $5 \mathrm{~cm}$ and $10 \mathrm{~cm}$. For each length, the quantity is set to $3(n=3)$. Inaccuracy in length is observed but it is consistent for all the readings. This observation indicates that the difference between the required length and the cut length, $|\Delta|$ is independent of the required length. Subsequently, the quantity is increases to $15(n=15)$ for each of the required length in Table 1. Given $n=15$ and by using (1), the RMSE is computed and obtained the values of $0.227 \mathrm{~cm}$ and $0.234 \mathrm{~cm}$, respectively for a required length of $5 \mathrm{~cm}$ and $10 \mathrm{~cm}$. The RMSE for both required lengths is quite close and agreed with an early observation from the tabulated data in Table 1.

To further quantify this observation, another set of experiments is conducted. The quantity is set to 1 whereas the length of the sheet is increased gradually by $1 \mathrm{~cm}$ within the range of $4 \mathrm{~cm}$ to $10 \mathrm{~cm}$ with a total of 7 measurements $(n=7)$. Table 2 shows the cutting results. The minimum and maximum of $|\Delta|$ are $0.2 \mathrm{~cm}$ and $0.5 \mathrm{~cm}$, respectively. Meanwhile, RMSE is computed using (1) for $n=7$ which obtained a value of about $0.344 \mathrm{~cm}$. The results of $|\Delta|$ and RMSE from a tabulated data in Table 2 is slightly bigger than $|\Delta|$ in Table 1 and previously computed RMSE which based on the extended data of Table 1 (i.e., $n=15$ for each of the required length). The main reason is because of the results in Table 1 are based on the continuous cutting process (i.e. quantity $>1$ for a required length). This discrepancy leads to an identification of two factors that 
causing inaccuracy in length. These factors are parallax error during the setting of zero position and the friction during the rolling process. The parallax error can be avoided by using the auto-zeroing sensor. Furthermore, the friction-less material can be used as a roller's material to ensure a fine rolling process. Both solutions could incur a high cost to the development of the automatic sheet cutter. The accuracy of the proposed automatic sheet cutter shown in Tables 1 and 2 are acceptable for the usage of household retail shops. The development of the automatic sheet cutter is considered as low cost as no advanced cutting technologies involved.

Table 2. Comparison of the required length and the cut length for quantity $=1$.

\begin{tabular}{ccc}
\hline Required Length $(\mathrm{cm})$ & Cut Length $(\mathrm{cm})$ & $|\Delta|(\mathrm{cm})$ \\
\hline 4 & 4.5 & 0.5 \\
5 & 5.3 & 0.3 \\
6 & 5.6 & 0.4 \\
7 & 7.4 & 0.4 \\
8 & 7.8 & 0.2 \\
9 & 9.2 & 0.2 \\
10 & 10.3 & 0.3 \\
\hline
\end{tabular}

\section{FUTURE WORKS}

The prototype of the automatic sheet cutter proposed in this study has not been considering the feedback between the roller and the main controller (i.e., Arduino). Given a situation, for example, the roller rolls the sheet and it reaches the end of the sheet. The system will continue to roll as this incident is not captured by the system. Therefore, for future improvement, limit switches are required at the roller to notify the system that this incident has occurred and the system returns an invalid measurement.

\section{CONCLUSION}

Automation is crucial to increase the productivity and quality of the product, and increase the efficiency of the material's usage. In SME household retailing businesses, process automation is needed to improve the manual process of measuring and cutting the mat or sheet made of rubber or PVC materials. The mat or sheet often use as a floor or table mat. A low-cost and portable automatic sheet cutter is proposed in this study to fulfills the demands in the household retailing field. The proposed design consists of three main parts which are Arduino-based controller circuitry, roller-cutter framework, and sheet racking tool. The sheet racking tool is following the existing design used in household retail shops. Therefore, the design of the rollercutter framework can be simply fitted to the existing sheet racking tool. The accuracy of the automatic sheet cutter is acceptable with a maximum deviation observed is $\pm 0.5 \mathrm{~cm}$ of the required length. The automatic sheet cutter costs reasonably cheap as no advanced cutting technologies involved.

\section{ACKNOWLEDGEMENT}

The authors would like to thank Universiti Teknikal Malaysia Melaka for providing instrumentation devices and financial supports to complete this project.

\section{REFERENCES}

[1] S. Engineering, "SM-400-TA Automatic X/Y Cutting System With Ultrasonic and Electric Rotary Cutting Tools," 2020. [Online]. Available: http://www.smre.it/sm-400-ta

[2] V. Mande and M. Lakhe, "Automatic vegetable leaf cutter based on Matlab and embedded systems," in International Conference for Convergence in Technology, 2018, pp. 1-4.

[3] Q. Zhang, H. Luo, W. Zhu, G. Qi, and Y. Wang, "Design and implementation of a automatic carpet edge-cutting system," in IEEE International Conference on Mechatronics and Automation, 2016, pp. 2582-2586.

[4] W. Shang and Q. Yan, "Vision-based automatic die-cutting system with high-precision," in IEEE International Conference on Information and Automation, 2015, pp. 1127-1131.

[5] M. Flemmer and L. Tang, "Computer vision for automatic accurate plasma arc cutting measurement," in International Conference on Mechatronics and Machine Vision in Practice, 2017, pp. 1-6. 
[6] C. T. Hsieh, "Developing low cost and smart laser-based paper cutter based on open source 3D printer," in IEEE International Conference on Advanced Manufacturing, 2018, pp. 109-112.

[7] J. W. Jung, J. W. Jeon, and Y. C. Kim, "Automation of glass cutting process for touch screen panel," in IECON Proceedings (Industrial Electronics Conference), 2016, pp. 60-65.

[8] S. Lakhe, A. Barve, R. Jangam, B. Talekar, V. Ratanparaj, and H. Bansod, "Design analysis \& fabrication of pneumatic pipe cutting machine," in IEEE International Conference on Engineering Technologies and Applied Sciences, 2018, pp. 1-7.

[9] V. Phakphonhamin and M. Chudokmai, "Optimizing the performance of the LECTRA automatic fabric cutting machine," in International Conference on Business and Industrial Research, 2018, pp. 282-287.

[10] Y. Sun and Q. Chen, "Control of a pipe-cutting machine," in International Conference on Measuring Technology and Mechatronics Automation, 2010, pp. 845-848.

[11] J. Hou and J. Mao, "Automatic control mechanism of cutting for the EBZ-160 roadheader," in International Conference on Future Computer and Communication, 2010, pp. V3-668-V3-671.

[12] M. Tong, D. Kang, and P. Liu, "Research on automatic section cutting control of roadheader," in International Conference on Measuring Technology and Mechatronics Automation, 2010, pp. 22-25.

[13] Y. Jiang, Z. Wu, and F. Tian, "Cutter setting calculation for CNC hobbing non-circular gear," in International Conference on Electric Information and Control Engineering, 2011, pp. 5784-5786.

[14] M. Yang, X. Li, T. Shi, and S. Yang, "Time series modeling and analysis of cutter wear in milling operation," in International Conference on Measuring Technology and Mechatronics Automation, 2011, pp. $1023-1026$.

[15] G. H. Liu and X. Luo, "Modeling and simulation of the height control system for cutter of cotton topcutting machine," in International Conference on Electronics, Communications and Control, 2011, pp. 2127-2130.

[16] F. Gao, S. Y. Wang, J. Gao, R. Li, and M. Wu, "Automatic control method research on pendulum speed of roadheader's cutting arm," in International Conference on Mechanic Automation and Control Engineering, 2011, pp. 4789-4791.

[17] F. Gao, S.-Y. Wang, R. Li, Z.-S. Yang, and M. Wu, "Automatic cutting start-up and shutdown control method of roadheaders," in International Conference on Automatic Control and Artificial Intelligence, 2012, pp. 578-580.

[18] W. Yu and L. Lu, "A route planning strategy for the automatic garment cutter based on genetic algorithm," in IEEE Congress on Evolutionary Computation, 2014, pp. 379-386.

[19] K. Chen, M. Han, Y. Wang, Z. Cai, and C. Qu, "A new automatic program to generate parametric model of shield cutter head," in IEEE/ASME International Conference on Mechatronic and Embedded Systems and Applications, 2016, pp. 1-6.

[20] A. A. Fomin, "Microgeometry of surfaces after profile milling with the use of automatic cutting control system," in International Conference on Industrial Engineering, Applications and Manufacturing, 2017, pp. 1-4.

[21] C. H. Su, H. H. Lin, M. H. Ho, and C. T. Huang, "Automatic die calibration for accurate punching for shoe making machine tools," in IEEE International Conference on Applied System Innovation, 2018, pp. 410-413.

[22] H. C. Chang, T. L. Chen, and C. L. Tsai, "Automatic storage and cutting system for metal bars," in IEEE Eurasia Conference on IOT, Communication and Engineering, 2019, pp. 8-9.

[23] H. Liu and J. Wang, "Research on design of the automatic steel wire-changing cutting device," in International Conference on Information Science and Control Engineering, 2017, pp. 1140-1143.

[24] J. Yuan, R. Guan, and J. Du, "Design and implementation of disc cutter changing robot for tunnel boring machine (TBM)," in IEEE International Conference on Robotics and Biomimetics, 2019, pp. 2402-2407.

[25] H. B. Lin, "The design of microcomputer automatic strip material cutter," in International Conference on Control Engineering and Communication Technology, 2012, pp. 174-176. 


\section{BIOGRAPHIES OF AUTHORS}
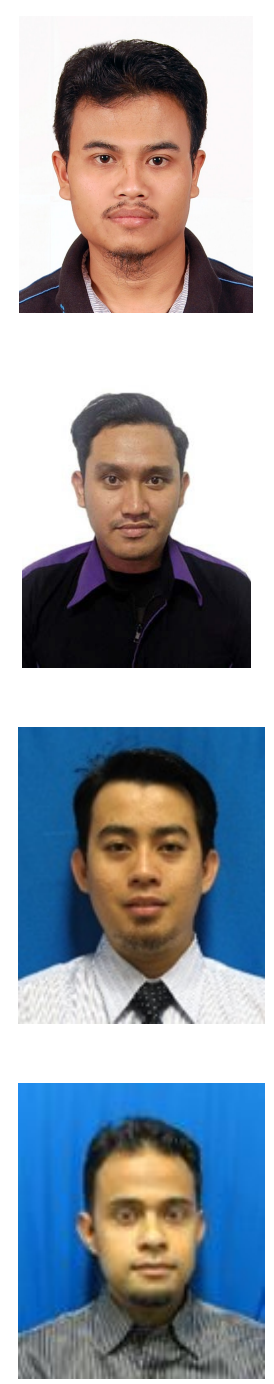

Mohd Syafiq Mispan received B.Eng Electrical (Electronics) and M.Eng Electrical (Computer and Microelectronic System) from Universiti Teknologi Malaysia, Malaysia in 2007 and 2010 respectively. He had experienced working in semiconductor industries from 2007 until 2014 before pursuing his Ph.D. degree. He obtained his Ph.D. degree in Electronics and Electrical Engineering from University of Southampton, United Kingdom in 2018. He is currently a senior lecturer in Fakulti Teknologi Kejuruteraan Elektrik dan Elektronik, Universiti Teknikal Malaysia Melaka. His current research interests include hardware security, CMOS reliability, VLSI design, and Electronic Systems Design.

Ahmad Hafizzuddin Mustafa received a Diploma of Electronic Engineering (Computer) from Ungku Omar Polytechnic (PUO), Malaysia. He is currently pursuing a Bachelor of Computer Engineering Technology (Computer Systems) at the Universiti Teknikal Malaysia Melaka.

Hafez Sarkawi received B.Eng Electrical (Electronics) from Universiti Teknologi Malaysia in 2007 and M.Eng (Industrial Electronics and Control) from Universiti Malaya in 2012. Currently, he is a Lecturer at the Fakulti Teknologi Kejuruteraan Elektrik dan Elektronik, Universiti Teknikal Malaysia Melaka and with the Advance Sensors \& Embedded Controls System (ASECs) research group. His research interests include power electronics and control systems such as DC-DC converter, robust control, and hybrid control.

Aiman Zakwan Jidin obtained his M.Eng in Electronic and Microelectronic System Engineering from ESIEE Engineering Paris France in 2011. He has 2 years of working experience in designing digital IC and digital system in FPGA at Altera Corporation Malaysia, before joining Universiti Teknikal Malaysia Melaka as lecturer and researcher, in Electronics and Computer Engineering. His research interests include FPGA Design and Digital System Design 